\title{
Amitriptyline and intraoral devices for migraine prevention: a randomized comparative trial
}

\author{
Amitriptilina e dispositivos intraorais para a prevenção da migrânea: estudo randomizado \\ e comparativo
}

Marco A. D. Bruno', Abouch V. Krymchantowski²

\begin{abstract}
Objectives: Nonpharmacological treatments, such as the Nociceptive Trigeminal Inhibition Tension Suppression System (NTI-tss), are approved for migraine prophylaxis. We aimed at evaluating the effectiveness of the NTI-tss and to compare its efficacy with amitriptyline and with a sham intraoral device in the preventive treatment of migraine. Methods: Consecutive patients with migraine were randomized to receive $25 \mathrm{mg}$ of amitriptyline/day $(n=34)$, NTI-tss $(n=33)$ and a non-occlusal splint $(n=30)$. The headache frequency was evaluated at six and 12 weeks. Results: The amitriptyline group showed, respectively, $60 \%$ and $64 \%$ reduction in attack frequency at six and 12 weeks $(P=0.000)$. In the NTI-tss and non-occlusal splint groups, reduction was $39 \%$ and $30 \%$, respectively, at six weeks and $48 \%$ for both groups at 12 weeks. Conclusions: Amitriptyline proved superior to the NTI-tss and the non-occlusal splint. Despite its approval by the United States Food and Drug Administration, the NTI-tss was not superior to a sham device.
\end{abstract}

Keywords: migraine disorders; amitriptyline; preventive medicine.

\section{RESUMO}

Objetivo: Tratamentos não farmacológicos como o Nociceptive Trigeminal Inhibition Tension Suppression System (NTI-tss), são aprovados para a prevenção da migrânea. Avaliamos a eficácia do NTI-tss no tratamento preventivo da migrânea e comparamos sua eficácia com a de um medicamento tradicional (amitriptilina) e com um dispositivo intraoral que não interfere com a oclusão (placa palatina). Métodos: Pacientes consecutivos com migrânea foram randomizados e receberam $25 \mathrm{mg}$ de amitriptilina/dia $(n=34)$, NTI-tss $(n=33)$ ou placa palatina não oclusal $(n=30)$. A frequência da cefaleia foi comparada após seis e 12 semanas. Resultados: No grupo da amitriptilina houve redução de $60 \%$ em seis semanas e de 64\% em 12 semanas ( $P=0.000)$. Nos grupos do NTI-tss e da placa não oclusal a redução foi respectivamente de 39\% e 30\% após seis semanas, e de $48 \%$ para ambos em 12 semanas. Conclusões: Amitriptilina foi superior ao NTI-tss e à placa palatina no tratamento da migrânea sem aura. O NTI-tss obteve resultados similares aos da placa não oclusal.

Palavras-chave: transtornos da enxaqueca; amitriptilina; medicina preventiva.

Migraine is a highly-prevalent primary headache ${ }^{1}$. It affects nearly $16 \%$ of the world's adult population with a higher prevalence in women ${ }^{2}$. Migraine is a neurological disorder leading to functional disability and drug therapy is often indicated, widely used and scientifically substantiated for acute treatment ${ }^{3,4}$. Prophylactic treatment is prescribed when attacks are frequent and disabling to the extent of interfering with the quality of life ${ }^{4}$. It is also indicated when symptomatic treatment proves inefficient, poorly tolerated or contraindicated ${ }^{4}$. Tricyclic antidepressants, such as amitriptyline, are widely employed to treat various pain conditions as well as to prevent migraine $e^{5,6}$.
In the anatomical field innervated by the trigeminal nerve, the jaw-opening reflex is equivalent to the nociceptive or flexor reflex and inhibits the activity of the mandibular elevator muscles when orofacial mechanoreceptors, located in the mucosa and periodontal ligament, are activated ${ }^{7}$. Based on this activation, as well as its potential relationship with headache mechanisms, an inhibitory device for intraoral use was developed and proposed for migraine and tension-type headache treatment ${ }^{8,9}$. It is called the Nociceptive Trigeminal Inhibition Tension Suppression System (NTI-tss) and has the structure of a prefabricated appliance that is fitted to the

\footnotetext{
'Universidade Federal Fluminense, Departamento de Neurologia, Niterói RJ, Brasil;

${ }^{2}$ Centro de Avaliação e Tratamento da Dor de Cabeça do Rio de Janeiro, Rio de Janeiro RJ, Brasil.

Correspondence: Marco A. D. Bruno; Rua Visconde de Pirajá 414 / 1106; 22410-002 Rio de Janeiro RJ, Brasil; E-mail: marcoadbruno@gmail.com

Conflict of interest:There is no conflict of interest to declare.
}

Received 12 September 2017; Received in final form 26 December 2017; Accepted 19 January 2018. 
upper central incisors, providing contact with the mandibular central incisors during mouth closure and avoiding contact with all other teeth.

The use of intraoral appliances may exert a beneficial effect on headaches, including migraine ${ }^{10}$. However, studies that investigated the efficacy of the NTI-tss in both headaches and symptoms of temporomandibular disorders (TMD) have yielded mixed results ${ }^{8,9,11,12}$.

The objectives of this study were 1) to assess the efficacy of the NTI-tss in reducing the frequency of migraine without aura attacks, 2) to compare its efficacy with the use of a traditional preventive migraine drug (amitriptyline), and 3) to compare its efficacy with a sham intraoral device that does not interfere with physical contact between upper and lower teeth (non-occlusal splint).

\section{METHODS}

The study was conducted from March 2010 to December 2013 in an outpatient headache clinic of a public university hospital in Rio de Janeiro, Brazil. Eligible participants were consecutive adults, aged between 18 and 70 years, who sought treatment at the premises. All patients were evaluated by an experienced neurologist and forwarded to a dentist specializing in orofacial pain, who used the Research Diagnostic Criteria for Temporomandibular Disorders guidelines ${ }^{13}$. In order to be eligible, the patients had to fulfill the criteria for migraine without aura according to The International Classification of Headache Disorders, $2^{\text {nd }}$ edition (ICH-2) $)^{14}$. In addition, other inclusion criteria were: 1) 1-2.5 attacks per week (4-10 per month) during the previous two months; 2 ) the presence of natural maxillary and mandibular anterior teeth or fixed dentures supported by natural teeth or osteo-integrated implants; 3) the presence of posterior natural teeth or teeth supported by osteo-integrated implants in both dental arches in sufficient number to ensure mandibular occlusal stability; 4) no upper and/or lower total dentures; and 5) a normal overbite and overjet (no more than $2 \mathrm{~mm}$ ). Exclusion criteria were: 1) undergoing orthodontic treatment; 2) the presence of periodontal disease; 3) acute signs and symptoms of TMD; 4) overuse of symptomatic medication for headache ${ }^{14}$; 5) an inability to fill out the headache and pain diary; 6) being pregnant or lactating, and 7) having a previous history of psychiatric disorder.

Among the 97 included patients, none reported acute pain in the region of the masseter and/or temporal muscles during chewing or speech, and no pain during either maximum mouth opening, or lateral mandibular movements and protrusion.

In the first group, patients were given $25 \mathrm{mg}$ of amitriptyline, taken daily as a single oral dose at night. The second group used the NTI-tss. The prefabricated appliance was individually adapted directly to the maxillary central incisors using self-curing acrylic resin. The appliance was installed and adjusted so that it attached to the upper dental arch and established contact with the two lower central incisors. Attention was given to make sure that the NTI-tss promoted disocclusion of the posterior teeth and canines, both in closing the mouth and in performing the movements of right and left laterality and protrusion, so that there would be no contact between the upper and lower teeth in any mandibular position. The device had not only to be well retained, but the patient should not have reported discomfort. In the third group, patients were given an intraoral non-occlusal splint. The palatal coverage was made from self-curing acrylic resin covering the entire hard palate. The appliance was adjusted so as not to interfere with mouth closure in habitual occlusion or with tooth contacts during mandibular movements. Both devices, the NTI-tss and non-occlusal splint, were supplied free of charge to the patients, as was amitriptyline.

The devices had to be worn at nighttime and during the day whenever the patient experienced symptoms of headache onset or even mild headache. Patients had to complete a headache diary recording the frequency of the headaches and other mouth or mandibular pain.

Return visits of all patients were scheduled to occur after six and 12 weeks, and they were reassessed by both the dentist and the neurologist. In addition, all patients were emphatically instructed about the importance of wearing the appliances, or taking the drug regularly.

Although the researchers knew in which group patients were being allocated, the studied patients were blind to the device type and were all highly motivated regarding the potential role of the intraoral devices for preventing migraine attacks. Additionally, data analysis and statistical evaluation was made by a third party who did not know the patient's group allocation. The study followed the recommendations of the Declaration of Helsinki and all patients signed an informed consent form. The study was approved by the local Ethics Committee (CAAE nº 0271.0.258.000-09).

\section{Statistical analysis}

Snedecor's F test analysis of variance (ANOVA) was used to analyze differences in the frequency among the three groups at the time the patients entered the study. The Kruskal-Wallis test was used to assess statistical differences among the three groups at the six and 12 week reassessments. The Friedman test was employed to evaluate the differences in each group individually at the different times. Finally, the one-way ANOVA test followed by Tukey's pairwise comparisons were applied to assess differences in the groups regarding the number of patients and age, and the chi-square test $\left(\mathrm{X}_{2}\right)$ for gender and marital status. The significance level was set at $\mathrm{P}<0.05$.

\section{RESULTS}

Ninety-seven patients were included. Thirty-four patients in the amitriptyline group, 33 in the NTI-tss group and 30 in 
the non-occlusal splint group. Seventy-six patients completed the study, 28 in the amitriptyline group, 25 in the NTI-tss group and 23 in the non-occlusal splint group (Figure 1). Reasons for not completing the study were: tolerability issues (five patients in the amitriptyline group reported severe drowsiness); inability to complete the diary (four patients in the NTI-tss group; four patients in the non-occlusal splint group) and loss to follow up (one in the amitriptyline group; four in the NTI-tss group and three in the sham device group).

The demographic data are shown in Table 1. There were no differences in gender, age and marital status among the groups.

The mean weekly frequency of headache attacks is shown in Table 2 and Figure 2. In the amitriptyline group, the frequency of attacks at baseline was 2.5 per week, 1.0 per week after six weeks and 0.9 after 12 weeks. The reduction was statistically significant both between the baseline and six weeks, as well as between the baseline and 12 weeks $(\mathrm{p}<0.01)$.
Table 1. Demographic data of 76 patients with migraine without aura before treatment with amitriptyline, the NTI-tss or non-occlusal splint.

\begin{tabular}{lccc}
\hline Variable & Amitriptyline & NTI-tss & $\begin{array}{c}\text { Non-occlusal } \\
\text { splint }\end{array}$ \\
\hline Patients (number) & 28 & 25 & 23 \\
\hline $\begin{array}{l}\text { Gender - } \mathrm{n}(\%) \\
\text { Female }\end{array}$ & $25(89.3)$ & $21(84.0)$ & $20(86.9)$ \\
\hline Male & $3(0.7)$ & $4(16.0)$ & $3(13.1)$ \\
\hline Age (years) - mean \pm SD & $39.75 \pm 12.5$ & $40.12 \pm 10.0$ & $38.48 \pm 11.0$ \\
Marital status (number) & & & \\
\hline Married & 17 & 14 & 13 \\
\hline Single & 8 & 9 & 8 \\
\hline Divorced & 3 & 2 & 2 \\
\hline
\end{tabular}

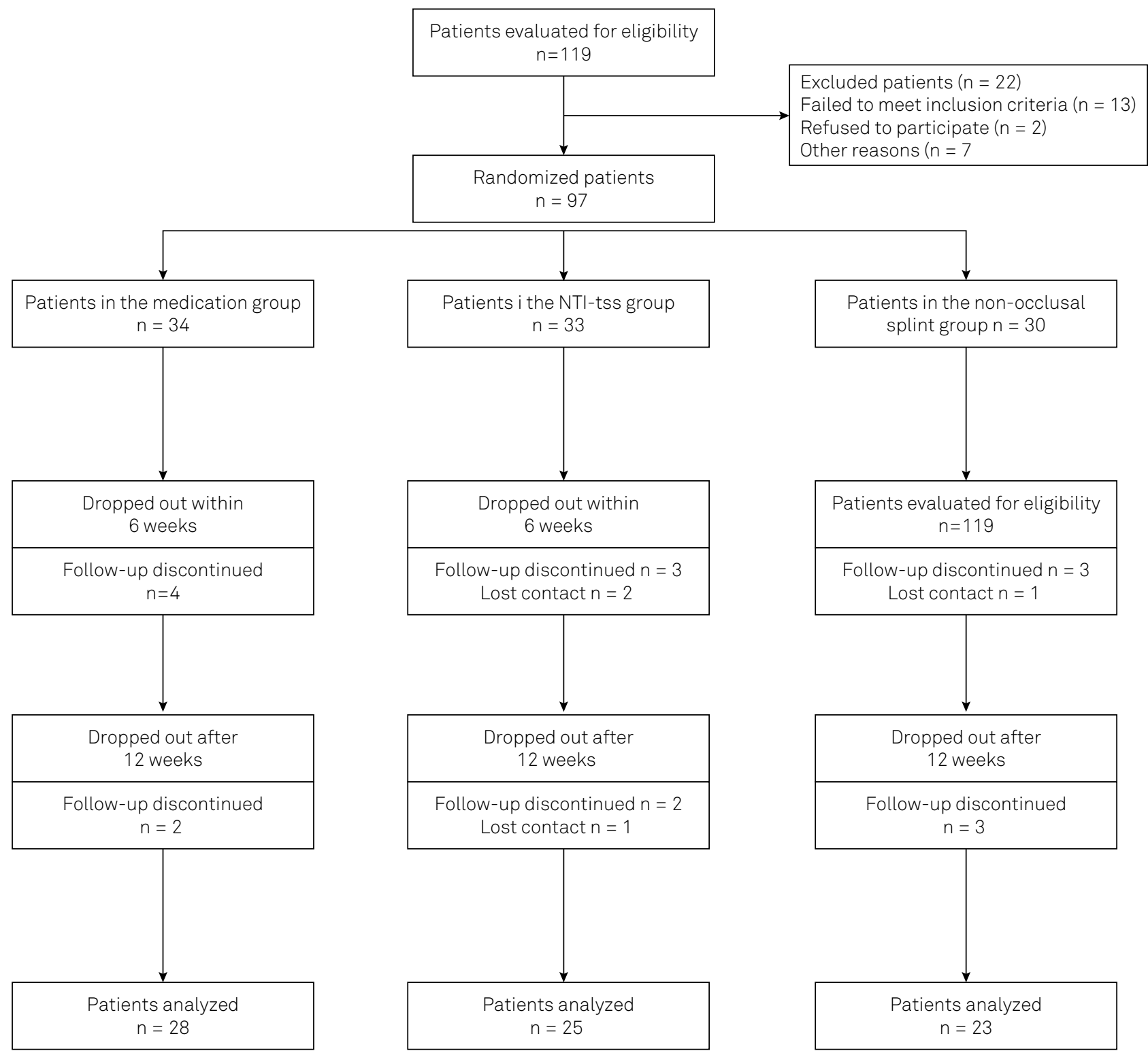

Figure 1. Study flow sheet. 
Table 2. Headache frequency and reduction in the three groups at the moment of entering the study and after 6 and 12 weeks of treatment (mean and standard deviation).

\begin{tabular}{|c|c|c|c|}
\hline Variable & Initial & 6 Weeks & 12 Weeks \\
\hline \multicolumn{4}{|l|}{ Amitriptyline } \\
\hline Frequency & $2.5(S D=0.6)$ & $1.0(\mathrm{SD}=0.2)$ & $0.9(\mathrm{SD}=0.3)$ \\
\hline Reduction (\%) & - & 60 & 64 \\
\hline \multicolumn{4}{|l|}{ NTI-tss } \\
\hline Frequency & $2.3(S D=0.6)$ & $1.4(S D=0.5)$ & $1.2(S D=0.5)$ \\
\hline Reduction (\%) & - & 39.1 & 47.8 \\
\hline \multicolumn{4}{|c|}{ Non-occlusal splint } \\
\hline Frequency & $2.3(\mathrm{SD}=0.6)$ & $1.6(S D=0.5)$ & $1.2(S D=0.4)$ \\
\hline Reduction (\%) & - & 30.4 & 47.8 \\
\hline
\end{tabular}

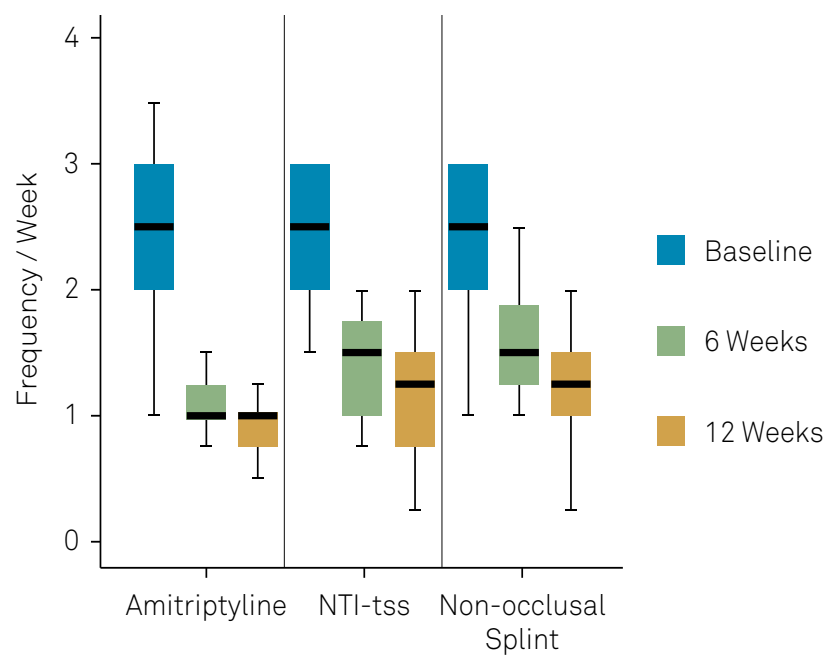

Figure 2. Frequency of headache attacks per week in groups A, $B$ and $C$ at baseline and after 6 and 12 weeks.

In the NTI-tss group, the frequency at baseline was 2.3 attacks weekly, 1.4 after six weeks and 1.2 after 12 weeks. The reductions were statistically significant when all times were compared $(\mathrm{p}<0.01)$.

The non-occlusal splint group had a baseline frequency of 2.3 attacks per week, 1.6 after six weeks and 1.2 attacks per week after 12 weeks. Comparisons between reductions at all times were significant $(\mathrm{p}<0.01)$.

After six weeks, there was a reduction in the three groups, but the amitriptyline group showed results statistically superior to both the NTI-tss group $(\mathrm{p}=0.003)$ and the non-occlusal splint group $(p=0.000)$. No difference was found between the NTI-tss group and the non-occlusal splint group $(p=0.641)$. Assessment at 12 weeks revealed that the amitriptyline group continued to show results statistically superior to the NTI-tss group ( $\mathrm{p}=0.032)$ and the non-occlusal splint group $(p=0.010)$. No differences were found between the NTI-tss and non-occlusal splint groups at 12 weeks $(\mathrm{p}=0.872)$.
The use of intraoral devices was well tolerated in both groups. No patient reported changes in sensitivity or increased tooth mobility related to the use of the appliances, and no patients withdrew because of tolerability issues in these two groups.

\section{DISCUSSION}

There is no consensus yet on the full pathogenesis of migraine and no single theory can explain the constellation of symptoms during headache attacks ${ }^{15}$. However, certain factors play a potential role in preventing the worsening of the headache and may therefore influence treatment outcome ${ }^{16}$.

Migraine is a neurovascular syndrome involving abnormal neuronal excitability in the cortex and central facilitation of pain associated with neurogenic inflammation, peripheral activation and sensitization ${ }^{17}$.

Peripheral factors may play a pathophysiological role in attack frequency ${ }^{17,18}$. Nociceptive afferents arising from muscles of mastication can enhance central sensitization, facilitating or contributing to headache escalation and chronicity. In addition, the reduction of sensory stimuli originating in the craniomandibular muscles can reduce central-sensitization ${ }^{19}$.

Amitriptyline is a tricyclic antidepressant effectively used in the prophylaxis of migraine independently of its antidepressant activity ${ }^{6}$. The present study corroborates previous findings about its efficacy ${ }^{5}$.

TheNTI-tss is a deviceapproved by the United States Food and Drug Administration for the prophylaxis of migraine9. However, its indication is controversial and not universally accepted $d^{11,12,19}$. This study showed that the effectiveness of the NTI-tss was lower than that of amitriptyline $(\mathrm{p}<0.05)$ and similar to the sham splint in the evaluations performed after six weeks and 12 weeks. The non-occlusal device efficacy was also statistically lower than that observed by the use of amitriptyline (Table 2).

The NTI-tss action is based on the assumption that an anterior stop point for the bite decreases muscle activity in both clenching and grinding of the teeth due to activation of the jaw-opening reflex ${ }^{8,9}$. There are studies suggesting that oral appliances with only anterior tooth contact may reduce the temporomandibular joint load ${ }^{20}$ and lead to lower electromyographic activity both in the masseter and anterior, as well as posterior, bundles of the temporalis muscle in awake individuals ${ }^{21}$. Although there is also evidence that the NTI-tss promotes an increased inhibitory effect on electromyographic activity of the masseter muscle during sleep when compared with a traditional stabilizing device, this reduction was not correlated with a decrease of pain observed with both a visual analog scale and muscle palpation ${ }^{22}$.

Temporomandibular disorders have been associated with various types of headache including migraine without aura ${ }^{23,24,25,26}$. The two disorders may share genetic and environmental factors and can result in abnormal processing of nociceptive afferents and sensitization of the trigeminal system ${ }^{25}$. 
Additionally, it has been hypothesized that excessive isometric contraction of the muscles of mastication, as may occur in some cases of bruxism, could increase the amount of nociceptive inputs to the brain stem, which could, in turn, trigger headache episodes during migraine $e^{8,9}$. Although some studies have shown that oral appliances used to control symptoms of TMD and reduce muscle activity can also reduce headaches ${ }^{10}$, the intraoral appliances used in the present study did not reduce migraine frequency significantly.

Potential adverse effects of the NTI-tss, such as changes in tooth position involving overeruptions of non-included teeth or intrusion of teeth involved in the NTI-tss contact and support ${ }^{27}$, swallowing or aspirating the device ${ }^{11}$, and joint pain ${ }^{28}$ did not occur in the present study.

Non-occlusal splints do not have areas of contact with the teeth of the opposing arch and, therefore, cannot mechanically alter the occlusion, or the position of the condyle in the glenoid fossa, or the vertical occlusion dimension. Therefore, if their use has any therapeutic effect at all, their mechanism of action probably stems from behavioral changes or some other nonspecific effect such as the patient's positive expectations regarding the treatment. Clearly, the therapeutic effect is not related to mechanical changes in the maxillomandibular relationship ${ }^{29}$. Due to these characteristics, we used a non-occlusal splint in our study as a control for the NTI-tss. Improvement by placebo effect is another important possibility ${ }^{30}$.

Some limitations of this study can be outlined. The patients were diagnosed according to $\mathrm{ICH}-2$ criteria, but the mean frequency of attacks before entering the study was subjectively reported by the patients and based on recall bias. No group was included to investigate the effect of time on the natural history of symptoms. The eventual possibility of a natural regression of migraine symptoms seems remote since the patients exhibited no changes or improvement in clinical conditions for long periods up until the moment that the interventions were introduced.

In conclusion, amitriptyline was significantly more effective in reducing the frequency of headache attacks of migraine without aura than the NTI-tss and non-occlusal splint. The NTI-tss showed similar results to that of the non-occlusal splint. The NTI-tss should not be recommended as a first-choice treatment for migraine without aura as it showed lower efficacy than amitriptyline and was similar to a non-occlusal splint.

\section{References}

1. World Health Organization. Atlas of headache disorders and resources in the world. Geneva: WHO; 2011.

2. Stovner L, Hagen K, Jensen R, Katsarava Z, Lipton $\mathrm{R}$, Scher A et al. The global burden of headache: a documentation of headache prevalence and disability worldwide. Cephalalgia. 2007 Mar;27(3):193210. https://doi.org/10.1111/j.1468-2982.2007.01288.x

3. Spierings EL. Mechanism of migraine and action of antimigraine medications. Med Clin North Am. 2001 Jul;85(4):943-58. https://doi.org/10.1016/S0025-7125(05)70352-7

4. Krymchantowski AV. Combining therapies for the treatment of migraine: is there a role? Expert Rev Neurother. 2005 Mar;5(2):145-7. https://doi.org/10.1586/14737175.5.2.145

5. Gomersall JD, Stuart A. Amitriptyline in migraine prophylaxis. Changes in pattern of attacks during a controlled clinical trial.J Neurol Neurosurg Psychiatry. 1973 Aug;36(4):684-90. https://doi.org/10.1136/jnnp.36.4.684

6. Couch JR, Ziegler DK, Hassanein R. Amitriptyline in the prophylaxis of migraine. Effectiveness and relationship of antimigraine and antidepressant effects. Neurology. 1976 Feb;26(2):121-7. https://doi.org/10.1212/WNL.26.2.121

7. Okeson J. Management of temporomandibular disorders and occlusion. 7th ed. St. Louis: Elsevier; 2013.

8. Shankland WE 2nd. Migraine and tension-type headache reduction through pericranial muscular suppression: a preliminary report. Cranio. 2001 Oct;19(4):269-78. https://doi.org/10.1080/08869634.2001.11746178

9. Shankland WE. Nociceptive trigeminal inhibition: tension suppression system: a method of preventing migraine and tension headaches. Compend Contin Educ Dent. 2002 Feb;23(2):105-8.

10. Ekberg E, Vallon D, Nilner M. Treatment outcome of headache after occlusal appliance therapy in a randomized controlled trial among patients with TMDs of mainly arthrogenous origen. Swed Dent J. 2002;26(3):115-24.
11. Jokstad A, Mo A, Krogstad BS. Clinical comparison between two different splint designs for temporomandibular disorder therapy. Acta Odontol Scand. 2005 Aug;63(4):218-26. https://doi.org/10.1080/00016350510019982

12. Stapelmann H, Türp JC. The NTI-tss device for the therapy of bruxism, temporomandibular disorders, and headache: where do we stand? A qualitative systematic review of the literature. BMC Oral Health. 2008 Jul;8(1):22. https://doi.org/10.1186/1472-6831-8-22

13. Dworkin SF, LeResche L. Research diagnostic criteria for temporomandibular disorders: review, criteria, examinations and specifications, critique. J Craniomandib Disord. 1992;6(4):301-55

14. The International Classification of Headache Disorders: 2 nd edition. Cephalalgia 2004;24 Suppl 1:9-160.

15. Burch R, Wells R. Pathophysiology of migraine. Headache. 2013 Feb;53(2):420-2. https://doi.org/10.1111/head.12027

16. Bigal ME, Lipton RB. Migraine chronification. Curr Neurol Neurosci Rep. 2011 Apr;11(2):139-48. https://doi.org/10.1007/s11910-010-0175-6

17. Puledda F, Messina R, Goadsby PJ. An update on migraine: current understanding and future directions. J Neurol. 2017 Sep;264(9):2031-9. https://doi.org/10.1007/s00415-017-8434-y

18. Drummond PD, Lance JW. Extracranial vascular changes and the source of pain in migraine headache. Ann Neurol. 1983 Jan;13(1):32-7. https://doi.org/10.1002/ana.410130108

19. Wright EF, Jundt JS. The NTI appliance for TMD and headache therapy. Tex Dent J. 2006 Dec;123(12):1118-24.

20. May BM, Garabadian C. Reducing condylar compression in clenching patients. Crit Rev Biomed Eng. 2000;28(3-4):389-94. https://doi.org/10.1615/CritRevBiomedEng.v28.i34.70

21. Becker I, Tarantola G, Zambrano J, Spitzer S, Oquendo D. Effect of a prefabricated anterior bite stop on electromyographic activity of masticatory muscles. J Prosthet Dent. $1999 \mathrm{Jul} ; 82(1): 22-6$. https://doi.org/10.1016/S0022-3913(99)70127-7 
22. Baad-Hansen L, Jadidi F, Castrillon E, Thomsen PB, Svensson P. Effect of a nociceptive trigeminal inhibitory splint on electromyographic activity in jaw closing muscles during sleep. J Oral Rehabil. 2007 Feb;34(2):105-11. https://doi.org/10.1111/j.1365-2842.2006.01717.x

23. Ciancaglini R, Radaelli G. The relationship between headache and symptoms of temporomandibular disorder in the general population. J Dent. 2001 Feb;29(2):93-8. https://doi.org/10.1016/S0300-5712(00)00042-7

24. Ballegaard V, Thede-Schmidt-Hansen P, Svensson P, Jensen R. Are headache and temporomandibular disorders related? A blinded study. Cephalalgia. 2008 Aug;28(8):832-41. https://doi.org/10.1111/j.1468-2982.2008.01597.x

25. Gonçalves DA, Speciali JG, Jales LC, Camparis CM, Bigal ME. Temporomandibular symptoms, migraine, and chronic daily headaches in the population. Neurology. 2009 Aug;73(8):645-6. https://doi.org/10.1212/WNL.0b013e3181b389c2
26. Franco AL, Gonçalves DA, Castanharo SM, Speciali JG, Bigal ME, Camparis CM. Migraine is the most prevalent primary headache in individuals with temporomandibular disorders.J Orofac Pain. 2010;24(3):287-92.

27. Klasser GD, Greene CS. Oral appliances in the management of temporomandibular disorders. Oral Surg Oral Med Oral Pathol Oral Radiol Endod. 2009 Feb;107(2):212-23. https://doi.org/10.1016/j.tripleo.2008.10.007

28. Wright EF. Manual of temporomandibular disorders. 2nd ed. Amis: Wiley-Blackwell, 2010.

29. Stohler CS. Interocclusal appliances: do they offer a biologic advantage? In: McNeill C, editor. Science and practice of occlusion. Chicago: Quintessence; 1997. p. 381-93.

30. Tfelt-Hansen PC, Hougaard A. Migraine: differential effects of placebos in migraine clinical trials. Nat Rev Neurol. 2014 Jan;10(1):10-1. https://doi.org/10.1038/nrneurol.2013.255 